\title{
PROJETO DE LEI N.० 2334/70, QUE REGULA AS ATRIBUIÇÕES DO TÉCNICO DE ENFERMAGEM
}

\author{
Esther de Figueiredo Ferraz
}

2.176/73 CE. $10^{\circ}$ e $2 .^{\circ}$ Graus

$07 / 11 / 73$

$5.450 / 73-\mathrm{CFE}$

O Sr. Ministro da Educação e Cultura, pelo ofício número 2.775-BSB/73, de 10 de outubro último, aqui chegado aos 25 do mesmo mês, transmite a este Conselho Federal de Educação a solicitação da Subchefia do Gabinete Civil da Presidência da República para Assuntos Parlamentares, no sentido de ser apreciado o Projeto de Lei n. ${ }^{\circ}$ 2.334/70 do nobre deputado Emílio Gomes, que "regula o exercício da enfermagem profissional e define as atribuições do Técnico de Enfermagem". Encarece Sua Excelência a urgência desse pronunciamento, porquanto o projeto está pronto para ser incluído na Ordem do Dia, para votação.

O projeto de lei em questão está assim vesado:

"O Congresso Nacional decreta:

Art. 1. 0 - Estender aos Técnicos de Enfermagem, portadores de diploma registrado no Ministério da Educação e Cultura, conferidos segundo os artigos 47 e 48 da Lei n. 4.024 , de 20 de dezembro de 1961, que fixa as Diretrizes e Bases da Educação Nacional, os benefícios instituídos peia Lei n. ${ }^{\circ} 2.604$, de 17 de setembro de 1955.

Art. 2.0 - Incluir no art. 3.0 da Lei n.o 2.604/55 o inciso "e" com a seguinte redação:

"e" - elaborar e subscrever os planos de cuidados de enfermagem e supervisionar sua execução. 
Art. 3.0 - São atribuições do Técnico de Enfermagem:

a) todas as atividades de enfermagem, excluídas as privativas do enfermeiro e enfermeiro obstetra, sempre sob a orientação deste;

b) assistir o enfermeiro responsável pela enfermagem, nas unidades de internação, em suas funções administrativas, exceto nos hospitais de ensino.

Art. $4^{\circ}$ - Esta lei entra em vigor na data de sua publicação, revogadas as disposições em contrário".

$\mathrm{Na}$ Comissão de Constituição e Justiça, foi reconhecida, unanimente, a constitucionalidade e juridicidade do projeto, o qual passou à Comssão de Saúde onde foi aprovado substitutivo apresentado pelo deputado Raphael Baldacci Filho, nos seguintes termos:

"O Congresso Nacional decreta:

Art. 1..$^{\circ}$ - Acrescente-se ao art. 2.0 da Lei n.o 2.604, de 17 17 de setembro de 1955, em lugar do item 3, o seguinte:

“3) Na qualidade de Técnico de Enfermagem, os portadores de diploma conferido após a conclusão de curso com currículo aprovado pelo Conselho Federal de Educação;

Os itens 3, 4, 5 e 6 passam, respectivamente, a construir os itens 4, 5, 6 e 7 .

Art. 2.0 - Acrescentem-se ao art. $3 .^{\circ}$ da Lei n. ${ }^{\circ} 2.604$, de 17 de setembro de 1955, em lugar do item 3, o seguinte:

seguinte redação:

"e) subscrever os planos de cuidado de enfermagem e supervisionar sua execução, obedecidas sempre as determinações médicas.

Parágrafo único - Os enfermeiros terão como auxiliares diretos os técnicos de enfermagem, cujas atribuições compreendem:

a) todas as atividades de enfermagem, excluídas as privativas do enfermeiro, sempre sob a orientação deste;

b) administração dos serviços de enfermagem, na falta de enfermeiro, ouvido o órgão fiscalizador competente".

Art. 3.0 - Esta lei entrará em vigor na data de sua publicação, revogadas as disposições em contrário".

Finalmente, na Comissão de Educação, opinou-se, unanimemente, nos termos do parecer do Relator, deputado Bezerra de Mello, pela aprovação do projeto, com a emenda aditiva oferecida pelo deputado Flexa Ribeiro no sentido de se acrescentar ao projeto mais um artigo, que passaria a ser o $4 .^{\circ}$, assim redigido: 
"Art. 4. - Os atuais Auxiliares re Enfermagem que tenham certificado de conclusão do curso ,oficialmente reconhecido, nos termos da Lei n.o 775, de 6 de agosto de 1965, e que preencham os requisitos complementares exigidos no parágrafo único deste artigo, ficam equipados, para todos os efeitos, inclusive os da presente lei, aos Técnicos de Enfermagem, mediante apostilamento dos respectivos certificados e enquadramento na carreira profissional correspondente.

Parágrafo único - São requisitos para obtenção do benefício a que se refere este artigo:

a) prova do exercício da profissão por mais de 8 (oito) anos ininterruptos; ou

b) prova de exercício de funções de chefia de serviços auxiliares de enfermagem em unidades hospitalares, pelo prazo de 2 (dois) anos, no mínimo; ou

c) prova de conclusão do curso ginasial ou equivalente, conjugado ao exercício da profissão por mais de 4 (quatro) anos ininterruptos".

\section{II - VOTO DO RELATOR}

Embora a Relatora reconheça a procedência dos argumentos invocados pelos ilustres autores do projetto e de seus sucessivos substitutivos para justificar a necesidade de regulamentar o exercício de uma profissão "cuja existência de fato é indiscutível à vista da própria existência dos profissionais formados em cursos com currículo aprovado pelo Conselho Federal de Educação", entenda "data maxima venia":

a) que se deveriam aguardar as normas que o Conselho Federal de Educação está elaborando, com base nos estudos realizados pelo Departamentos de Ensino Médio do Ministério da Educação e Cultura, através de seu Laboratório de Currículos, no sentido de fixar os mínimos a serem exigidos nas várias habilitações profissionais cu conjunto de habilitação afins, na área da Saúde, aí incluídas as de Enfermagem (Técnico de Enfermagem - Auxiliar de Administração Hospitalar - Auxiliar de Documentação Médica Auxiliar de Fisioterapia - Auxiliar de Reabilitação - Secretária de Unidade de Internação - Auxiliar de Nutrição e Dietética Visitadora Sanitária) para, só depois, levar a cabo aquela regulamentação;

b) que se deveria aproveitar a oportunidade para reformular toda a legislação que regula o exercício da enfermagem profissional. certo como é que a Lei n.o 2.604, de 17/9/55, assim como o Decreto 
n..$^{50.387}$, de 28/03/61, que a regulamenta, estão completamente clesatualizados frente as novas leis que fixam diretrizes e bases para a educação nacional, nos vários graus de ensino (Lei n.o 5.4540/69, Decreto-lei n. ${ }^{\circ} 464 / 69$ e Lei n.o 5.592/71).

\section{Realmente:}

Este Conselho Federal de Educação está empenhado, no âmbito da competência que lhe fixou o art. $4 .^{\circ}$, § $3 .^{\circ}$, da Lei n.o 5.692/71, em fixar os mínimos a serem exigidos nas várias habilitações profissionais (ou conjuntos de habilitações afins) na área da saúde. Inclusive está revendo o próprio currículo mínimo para a habilitação - Técnico em Enfermagem - o qual fora, ao lado de muitos outros disciplinado no Parecer n..$^{\circ}$ 45/72.

Assim sendo, tudo indica que seria medida da mais elementar prudência aguardar que chegassem a seu termo esses trabalhos, dada

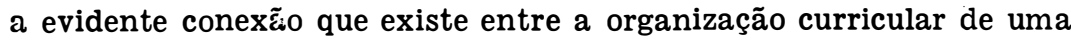
habilitação e sua regulamentação do ponto de vista profissional. Embora se trate de matérias distintas seu íntimo relacionamento está a exigir essa medida cautelar, que em nada virá prejudicar as legítimas aspirações e os intereses dos Técnicos de Enfermagem. Hão de preferir estes que sua profissão seja bem regulamentada, sem o perigo de confusões com as atividades desempenhadas pelos enfermeiros, em nível superior, e pelos auxiliares de enfermagem, a nível de estudos de $10^{\circ}$ grau, a que seja regulamentada quase que "por exclusão", como se vê do texto do Projeto de Lei n. ${ }^{\circ}$ 2.334-A/70 e de seus substitutivos.

Por outro lado, terminados que fossem esses trabalhos do Conselho Federal de Educação, estaríamos no 'momento histórico' para proceder a uma revisão de toda a legislação que regula o exercício da Enfermagem, legislação essa que ou é anterior à própria Lei de Diretrizes e Bases, a de n. ${ }^{\circ}$ 4.024, de 20/12/61, ou aos outros diplomas que a revogaram e substituíram no âmbito do ensino superior ou do ensino de $1 .^{\circ}$ e $2 .^{\circ}$ graus (Lei n. $.^{\circ} 540 / 68$, Decreto-lei n. ${ }^{\circ} 464 / 69$ e Lei n. ${ }^{\circ}$ 5.692/71). Atividades outras, que não a Enfermagem propriamente dita, surgiram no plano das profissões ligadas à saúde, e seria extremamente aconselhável que todas essas alterações, reflexos de nosso indiscutível desenvolvimento, se refletissem no novo diploma a ser afinal promulgado. Seria este, assim, um corpo orgânico e sistemático de preceitos, ao invés de uma colcha de retaJhos na qual se procura, a cada instante, inserir um pequeno fragmento.

Uma palavra, enfim, a respeito da emenda aditiva apresentada pelo ilustre deputado Flexa Ribeiro e aceita pela Comissão de Educação. Pretende, essa emenda, sejam equiparados aos Técnicos de 
Enfermagem os atuais Auxiliares de Enfermagem que preencham as condições previstas nas três alternativas ("a", "b" ou 'c") contidas no parágrafo único do art. 4..

Somos inteiramente contrária a essa equiparação, como contrária aqualquer equiparação baseada numa indistinção dos vários graus do ensino. Por mais qualificados que seja um auxiliar de enfermagem, levando-se em conta o exercício profisisonal, jamais poderá ele - do ponto de vista de sua formação geral - ser confunciido com um Técnico de Enfermagem. E o mesmo se dirá do Técnico de Enfermagem que pretendesse - apenas graças a experiência adquirida na profissão - ser tido como um enfermeiro diplomado por curso superior. A cada grau escolar há de corresponder um certo nível de habilitação, e não será "ex vi legis" que se conseguirá o milagre de transformar o menos em mais.

Para esse efeito, aí está o ensino supletivo com todas as suas “aberturas", permitindo ao profissional que queira ascender na escala social e funcional continuar seus estudos servindo-se dos cursos e exames amplamente postos à sua disposição.

Entendemos, pois, que nesses termos se poderá responder ao $\mathbf{S r}$. Ministro da Educação e Cultura a quem deverá ser remitido - para ilustrar, como um elemento a mais, a argumentação que acabamos de desenvolver - o texto do Parecer s/n.', aprovado na Câmara de Ensino de $1 .^{\circ}$ e $2 .^{\circ}$ graus, aos 10/09/73, relativo às "habilitações profissionais, ao nível de $2 .^{\circ}$ grau, na área de Saúde", parecer esse introdutório a uma série de outros mais que estão sendo elaborados para disciplinar cada uma dessas habilitações.

\section{III - CONCLUSÃO DA CÂMARA}

A Câmara de Ensino de $1^{\circ}$ e 2.0 Graus aprova o voto da Relatora. Sala das sessões, em 06 de novembro de 1973. (a.) Terezinha Saraiva - Vice-Presidente, Esther de Figueiredo Ferraz - Relatora, Paulo Nathanael, Edília Coelho Garcia, Valnir Chagas:

\section{IV - DECISÃO DO PLENÁRIO}

O Conselho Federal de Educação, em sessão plenária, aprova a conclusão da Câmara de Ensino de $1 .^{\circ}$ e 2.0 Graus nos termos do voto do Relator.

Sala Barretto Filho, em Brasília, DF, 07 de novembro. de 1973. 